\title{
DEMOCRACIA, MOVIMENTOS SOCIAIS E NIVELAMENTO INTELECTUAL: considerações sobre a ampliação da participação política
}

\author{
Maria Victória Espiñeira* \\ Helder Teixeira ${ }^{* *}$
}

\begin{abstract}
Este artigo tem por tema a questão da legitimidade democrática sublinhando, para tanto, os limites da democracia representativa e as potencialidades represadas dentro do espectro político atual brasileiro da ação individual e coletiva, suplantando o viés quantitativo que predomina nas análises sobre o processo democrático no Brasil. Para além das variáveis tradicionalmente assentadas na tríade voto, partidos políticos e eleições, o artigo procura demonstrar que a democracia eleitoral brasileira ainda não consolidou uma cultura política democrática, na medida em que vem solidificando um plano de diferenciação entre representantes e representados, decorrente de mandatos cada vez mais imperativos e menos afeitos ao controle e à participação dos representados. Pesquisas quantitativas, fontes primárias, secundárias e a análise de movimentos sociais recentes no cenário nacional permitiram construir a hipótese aqui trabalhada de que o processo eleitoral, por si mesmo, não responde pela construção e consolidação de uma democracia plural e participativa.

PALAVRAS-CHAVE: democracia, representação, movimentos sociais, esfera pública, accountability.
\end{abstract}

Nos debates recentes, vem se desenhando, de forma sistemática, algumas alternativas no sentido de reduzir-se o hiato entre os representantes e representados. No decorrer da história, vários mecanismos têm sido criados e propostos para esse fim. O clássico trabalho de Bernard Manin, The Principles of Representative Government (1997), apresenta vasta contribuição, recuperando um período extenso da trajetória do governo representativo, estudando desde a seleção dos cargos públicos para Atenas, as diversas formas de eleições na história e as diversas mudanças do governo representativo, passando pelo parlamentarismo, até a democracia de partidos e a de "audiência".

O que propomos aqui é apresentar aspectos que podem ser considerados cruciais na efetivação da aproximação entre esses dois gru-

* Doutora em Ciência e Filosofia da Educação. Mestra em Ciências Socias. Professora Adjunta do Departamento de Ciência Política e da Pós-Graduação em Ciências Sociais da Universidade Federal da Bahia. Rua Aristides Novis, 197. Cep: 40.210-909. Federação. Salvador - Bahia - Brasil. victoria@ufba.br

** Doutorando em Ciências Sociais da UFBA. helder.teixeira@yahoo.com.br pos de governantes (os representantes e os representados), considerando duas linhas de reflexão: aquela que entende que os representados só diminuem esse afastamento através de ações pedagógicas, presente nos estudos de John Dewey, posição que se refere à esfera individual da qualificação do individuo como ser político; e uma segunda que se relaciona com a dimensão coletiva, voltada para a atuação dos movimentos sociais na esfera pública.

Tomamos algumas evidências que demonstram a existência de um déficit da democracia representativa, apresentando dados sobre o Brasil, que se reportam à ausência de um elemento constitutivo básico no governo dos representantes, qual seja, a prestação de contas e a presença ainda constante do "mundo do segredo". Bobbio (2000) refere-se à importância da redução do "espaço do segredo", da qual depende o vigor de uma sociedade pluralista, como a democrata.

Esta análise ressalta a complexidade do tema, lembrando que, desde a Guerra de Peloponeso, Tucídides já reconhecia os dilemas ou dificuldades da relação entre governantes e governados, ao se referir à prática política de Péricles, cuja força de 
atuação estava em governar pelo povo e não com o povo. Diferentemente de Creonte, cuja atuação política ocorria através de vínculos estreitos em assembléias com os representados, mas de natureza demagógica. É claro que Péricles, quando se afasta de um governo “com o povo", estava deixando um dos princípios de um governo democrático. Mas o que nos interessa aqui é reforçar o sombreamento da força da retórica, que, muitas vezes, se sobrepõe ao conteúdo do bem público, com a intenção de “aproximação” com os representados.

Buscamos discutir, neste artigo, algumas formas de abuso do poder político, subjacentes na vigência de democracias representativas, como a restrição participativa dos cidadãos, fomentada pela oligarquização político-partidária que, após os resultados das eleições, utiliza-se desse expediente para legitimar o distanciamento entre representantes e representados.

Para além das questões relacionadas à proporcionalidade e à identidade entre eleitor e eleito, o elemento detectado para a consolidação desse modelo segregador de democracia foi o da pretensa qualificação do representante, como indivíduo distintamente preparado para o exercício do poder político, em detrimento do representado.

Assim, a nossa abordagem recusa um modelo monolítico de democracia e propõe um debate sobre a importância da sua dimensão inclusiva, a partir de um critério qualitativo da formação e edificação intelectual do cidadão, enfatizando o papel dos movimentos sociais nesse aprimoramento. Objetiva-se, com isso, destacar e resgatar a democracia como ideia que envolve um sistema de valores, e não apenas sublinhar sua vertente institucional, político-partidária, eleitoral e representativa.

Diante de um modelo que paulatinamente se afasta das origens e princípios da soberania popular, urge refletir sobre as causas que vituperam não apenas o processo democrático, mas o próprio sentido da política como esfera racional para dirimir as complexas aspirações inclusivas oriundas das camadas mais fragilizadas e marginalizadas da população. Como resolver, então, esses impasses?
Assim, o artigo discute dois modelos de relação entre representantes e representados, que se referem (como já enunciamos): um, à esfera individual de qualificação do indivíduo como ser político; e, o outro, que privilegia a dimensão coletiva de atuação desses indivíduos, através dos movimentos sociais, capazes de constituir um elo conectivo entre representantes e representados mais do que a exclusiva operacionalidade instrumental dos partidos políticos.

Isso implica dilemas analíticos no domínio da constituição e construção dos sujeitos sociais, capazes não só de fornecer informações sobre o que ocorre de pronto na sociedade civil e, assim, funcionar como sensores do sistema político, como também de tornar visíveis as demandas sociais, orientando, desse modo, as ações dos representantes no nível político-partidário.

Resumindo, iniciamos com a apresentação teórica dos dois modelos que subsidiam a desigualdade do processo de representação política, entre governantes e governados. Em seguida, trazemos algumas evidências da realidade brasileira, indicativas de abuso de poder, pela inexistência de instrumento de controle social pelas casas Legislativas, e que resultam em distanciamento, descrédito e desconfiança entre os cidadãos e seus representantes. Concluímos com a indagação sobre modelos alternativos ao conservantismo procedural da democracia, a partir da qual se discute a questão da qualificação intelectual como ferramenta de nivelamento democrático, de John Dewey, e demonstrando o papel dos movimentos sociais na formação de uma pedagogia política de aprendizado da democracia e de ampliação do espaço público democrático, o que se relaciona com a dimensão coletiva.

\section{REPRESENTAÇÃOEDESIGUALDADE: a diferenciação intelectual entre governantes e governados}

A distinção artificial entre governantes e governados tem assinalado uma espécie de lógica redundante nos procedimentos políticos das de- 
mocracias modernas, que se restringem, basicamente, às eleições como mecanismo-chave de mensuração da qualidade e do alcance da representação política. Por mais que não se subestime a importância desse instituto, o pleito eleitoral típico ainda se revela incompleto e contestável, na medida em que não se furtou ao complexo ditame das relações entre governantes e governados, que apresenta ainda características de oligarquização, circunscrição e concentração das esferas políticas decisórias em detrimento da legitimidade continuada dessa mesma relação.

Assim sendo, a excessiva relevância colocada nas eleições e nos procedimentos técnicos e rotineiros dos processos legislativos é insuficiente para se mensurar o efetivo sentido da democracia como relação proporcional entre governantes e governados, tendo em vista que o poder é considerado exclusivamente no exercício institucionalizado. O nexo dessa argumentação é que seu princípio se fundamenta, nas democracias representativas modernas, na soberania popular, sendo, além disso, despersonalizado e despatrimonializado; um "lugar vazio”, na acepção de Claude Lefort (1991).

A ênfase colocada no processo eleitoral e seus desdobramentos faz com que as democracias representativas fomentem a marginalização, a coadjuvação e a restrição dos governados frente aos interesses públicos concentrados nos representantes. Logo, ascende uma nova forma de abuso do poder político sem, contudo, exercer-se sob a forma instrumental típica das ditaduras, tais como a repressão, o extermínio e a supressão das oposições. É a própria dimensão representativa, eleitoral e congressual da democracia moderna que institui uma impossibilidade concreta de se conter essa usurpação e esse abuso da soberania e do poder popular.

Desse modo, o que se descortina de tais relações, diferenciadoras do exercício do cargo político eletivo a partir do voto que o justifica, é que o princípio de tal violação não mais se aloca no plano material da força, mas na incorporação de valores democráticos como justificativa para a exclusão pós-eleitoral dos representados. A valoração extrema dos resultados das urnas distorce a qualidade do exercício do poder político, de modo a justificar a conduta abusiva dos mandatários. Consequentemente, o representante eleito se utiliza do resultado das urnas de modo a não prestar contas de suas ações e decisões, tendo em vista ter conquistado sua vaga a partir de sua competência, capacidade e respaldo intelectual.

Na história recente da política brasileira, o resultado das urnas tem sido constantemente evocado para justificar o abuso do poder legitimamente assentado na vontade popular, mas corruptamente adequado às razões das oligarquias partidárias. Presidentes distintos, como Fernando Collor (19901992) e Fernando Henrique Cardoso (1994-2001), utilizam-se da justificativa das urnas para combater qualquer tipo de contestação às suas diretrizes governamentais. Parecem, com isso, defender a argumentação de Montesquieu de que o povo é sábio para escolher os governantes, mas não para governar (Montesquieu, 2000). Porém a Constituição de 1988 assegura, em seu Art.5, LXXIII, que

qualquer cidadão é parte legítima para propor ação popular que vise a anular ato lesivo ao patrimônio público ou de entidade de que o Estado participe [...], ficando o autor, salvo comprovada má fé, isento de custas judiciais e de ônus da sucumbência (Brasil, 2007).

O que parece ser uma lógica distorcida é, essencialmente, aquilo que o processo político reflete em sua dimensão mais concreta. Dos mandatários tradicionais aos políticos profissionais das democracias modernas, todos se portam na perspectiva de que a autoridade possui uma justificativa para tal exercício (Weber, 1993, 2005). Portanto, por mais que o esforço em compensar as diferentes formas de poder político, do autoritarismo à democracia, distinga a origem do próprio poder, parece que a máxima de Robert Michels (1968) - de que a oligarquização partidária promoverá a distinção entre líderes e liderados de modo irreversível - se faz cada vez mais atual. E isso decorre, mormente, da postura de diferenciação intelectual que se faz presente no instante em que um cidadão objetiva adentrar no jogo político-partidário.

Desse modo, a democracia moderna, fun- 
damentada em normas gerais que permitem aos membros da sociedade resolver conflitos, não realizou grande parte de suas promessas. De acordo com Bobbio, um dos grandes impedimentos foi a persistência das oligarquias, que, mesmo se adaptando historicamente à modernidade das relações econômicas e sociais, impediu uma maior participação, inclusão e socialização das decisões políticas (Bobbio, 2002b, 2003). Além disso, esse fenômeno se desdobra na insegurança do indivíduo, no que se refere à busca pela sobrevivência material, pois que o Estado, antigo senhor absoluto das relações sociais, foi sendo substituído por uma sociedade civil mais contestadora e interventora (Baumann, 1999).

De tal modo que, na medida em que se ampliou a liberdade individual, o poder público profissionalizado e racionalizado desfez a idéia de pertencimento do cidadão em sua comunidade, dado que a hierarquização necessária das relações de poder e a liberdade de atuação do mercado não prescindem da solidariedade para uma integração social (Habermas, 2003).

Mais uma vez, a questão se situa no fato de que a ampliação dos direitos e liberdades individuais, mais concretamente depositadas na ampliação e universalização do voto, não pode ser desconsiderada. O problema é que tal expansão dos direitos políticos não produziu necessariamente uma verdadeira relação de proporcionalidade entre o direito de escolha e a participação efetiva do cidadão nos processos políticos de relevância (Sartori, 1994). Mas, ao que parece, o processo eleitoral, como fundamento jurídico concreto do exercício da soberania popular, não tem preenchido os anseios da sociedade civil em escala mundial. Nesse sentido, cada vez mais são sugeridas formas de exercício mais direto de controle social das ações governamentais (Fisher; Sharp, 1998).

Ou seja, por mais que as discussões de ordem teórica tenham contribuído para a análise das relações de poder entre governantes e governados, são poucas as propostas de controle horizontal das ações de governo, assim como as perspectivas de que, nas sociedades contemporâneas, as oligarquias político-partidárias considerem a possibilidade de ampliação, ou mesmo criação e reprodução de instrumentos de controle down-top (Susskind; Cruikshank, 1987). Em que pese a importância de trabalhos recentes que demonstram algumas experiências que têm possibilitado a aproximação entre os representantes e representados através de práticas participativas no campo das instituições, ${ }^{1}$ alguns desses estudos partem do reconhecimento de que existem limites na democracia representativa e procuram romper com posições que acreditam que o mundo das virtudes está apenas em um lado, ou na sociedade ou no Estado (Lavalle, 2006; Urbinati, 2007; Laydet, 2004).

O problema das relações de poder entre governante e governados aparentemente não se limita ao abuso da autoridade constituída e envolveria uma esfera ainda mais distante de controle pela sociedade, na medida em que o maior dos abusos estaria na dificuldade colocada pelos governantes em se fazerem cidadãos comuns numa democracia substantiva de procedimentos (Cohen; Arato, 1999).

A ausência desse instrumento por parte das Casas Legislativas, em diferentes instâncias, tem reforçado maior distanciamento entre governantes e governados, reiterando uma concepção da democracia restrita à democracia procedimental e fomentando déficits de representação, desconfiança e descrédito na relação entre governantes e governados. A seguir, apresentamos algumas evidências brasileiras sobre o controle social das Casas Legislativas, com base em dados da Transparência Brasil.

\section{REPRESENTAÇÃO, DESCONFIANÇA E DES- CRÉDITO: alguns dados sobre controle social no desempenho do legislativo, no Brasil}

Ao que parece, o descrédito e a rejeição pelos quais passam os partidos políticos e as instituições políticas clássicas no Ocidente estão rela-

${ }^{1}$ Autores como Avritzer e Pereira (2005, p. 16) preferem chamar instrumentos como o orçamento participativo de "instituições hibridas", pois "envolvem um partilhamento de processos deliberativos entre atores estatais e atores sociais". 
cionados ao contínuo desencaixe entre o "cidadão comum” e as elites políticas (Beitz, 1989). Quanto maior for o desnível econômico e intelectual entre essas duas extremidades do processo político moderno, maior é a desconfiança para com os políticos e as instituições democráticas (Vazquez, 2001). E, se examinarmos com atenção a nossa socialização, veremos que chegamos aos dias atuais com o predomínio de uma matriz elitista, como demonstra Luis Felipe Miguel (2002), com base em filósofos como Nietzche e Ortega y Gasset.

Essa falta de credibilidade pode se observada a partir dos dados da Tabela 1, fruto de uma pesquisa realizada pelo Programa das Nações Unidas para o Desenvolvimento (PNUD, 2004) sobre a democracia na América Latina.

Os dados indicam o quão distantes se en-

Tabela 1 - Percepções sobre as razōes de descumprimento de promessas eleitorais

\begin{tabular}{l|c}
\hline $\begin{array}{l}\text { Os governantes cumprem suas promessas } \\
\text { eleitorais }\end{array}$ & 2,3 \\
\hline $\begin{array}{l}\text { Não cumprem porque ignoram como os } \\
\text { problemas são complicados }\end{array}$ & 10,1 \\
\hline $\begin{array}{l}\text { Não cumprem porque aparecem outros } \\
\text { problemas mais urgentes }\end{array}$ & 9,6 \\
\hline $\begin{array}{l}\text { Não cumprem porque o sistema não os } \\
\text { deixa cumprir }\end{array}$ & 11,5 \\
\hline $\begin{array}{l}\text { Não cumprem porque mentem para ganhar } \\
\text { as eleições }\end{array}$ & 64,7 \\
\hline Nenhuma das anteriores & 1,7 \\
\hline
\end{tabular}

Fonte: Pergunta P25U da Seção Proprietária do PNUD, pesquisa Latinobarômetro 2002.

Nota: $\mathrm{n}=19.279$

contram os parlamentos e seus respectivos parlamentares da sociedade civil. No caso específico brasileiro, esse distanciamento se acentua ainda mais na medida em que, sendo um Estado Federado, a relação entre representantes e representados se desdobra ainda nas esferas estaduais e municipais.

Para trazer algumas evidências sobre o distanciamento entre representantes e representados no Brasil, tomamos por base os dados da Transparência Brasil (2008), sobre a situação da maioria das Assembléias Legislativas dos Estados em relação à publicização de informações sobre o seu funcionamento (Tabela 2).
Constata-se que, na esfera legislativa federal, somente a Câmara dos Deputados disponibiliza números sobre a atividade e os gastos dos deputados, o que corrobora os argumentos até aqui apresentados sobre o caráter oligopolizado na democracia representativa hodierna, com novas roupagens de abuso de poder político, o que se expressa, particularmente, em manobras evasivas de não prestação de contas dos representantes de suas ações aos representados.

A análise da Tabela 2 explicita a existência ou não de difusão de informações sobre o funcionamento das Casas Legislativas aos seus cidadãos. Ela está ordenada segundo o maior índice do custo de manutenção de cada Casa Legislativa para o cidadão, tomando por base quatro indicadores: a) Presença em plenário; b) Presença em comissões; c) Verba de gabinete; d) Viagens. Esses indicadores, correlacionados ao custo de manutenção de um parlamentar por município, permitem avaliar, de acordo com a metodologia aplicada pela Transparência Brasil, a conduta de parlamentares e da Casa em relação aos representados. A publicização de informações dos parlamentos constitui prática e conduta que contribui para a criação de um elo conectivo com a sociedade civil, que patrocina e legitima o funcionamento das Casas Legislativas, possibilitando um aperfeiçoamento qualitativo da democracia.

No entanto - e esse é o elemento mais importante a ser ressaltado-, o Relatório da Transparência Brasil revela que o grau de publicização das atividades parlamentares, nas respectivas Casas Legislativas brasileiras, é extremamente baixo. A situação de cada Casa Legislativa em relação aos quatro indicadores levantados pela Transparência Brasil, corroboram esta conclusão e servem de elemento importante para se avaliar a relação pública entre os Legislativos e a sociedade civil. Os dados são apresentados na Tabela 2.

Nota-se, sobremaneira, a ausência de prestação de contas na maioria das Assembléias Legislativas do Brasil. A única Casa Legislativa que disponibiliza informações nos quatro quesitos pesquisados pela Transparência Brasil é a Assem- 
Tabela 2 - As Casas Legislativas que mais pesam no bolso do cidadão

\begin{tabular}{|c|c|c|c|c|c|}
\hline Casa Legislativa & $\begin{array}{c}\text { Presença em } \\
\text { Plenário }\end{array}$ & $\begin{array}{c}\text { Presença em } \\
\text { Comissões }\end{array}$ & $\begin{array}{l}\text { Verba de } \\
\text { Gabinete }\end{array}$ & Viagens & $\begin{array}{c}\text { Custo per } \\
\text { capita }(\mathbf{R S})\end{array}$ \\
\hline Roraima- RR & NÃO & NÃO & NÃO & 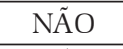 & 145,19 \\
\hline Acre- AC & NÂO & NÃO & NÃO & 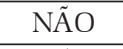 & 112,13 \\
\hline Amapá-AP & NÂO & NÃO & $\mathrm{NA \tilde {O }}$ & $\mathrm{NA \tilde {O }}$ & 110,23 \\
\hline Distrito Federal-DF & $\mathrm{NA \tilde {O }}$ & NÃO & SIM & $\mathrm{NA \tilde {O }}$ & 99,14 \\
\hline Rondônia -RO & $\mathrm{NÂO}$ & $\mathrm{NA \tilde {O }}$ & $\mathrm{NÂO}$ & $\mathrm{NA \tilde {O }}$ & 67,57 \\
\hline Sergipe-SE & SIM & NÃO & 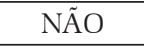 & 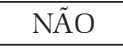 & 65,01 \\
\hline Mato Grosso do Sul-MS & $\mathrm{NA \tilde {O }}$ & NÃO & $\mathrm{NA \tilde {O }}$ & $\mathrm{NA \tilde {O }}$ & 63,65 \\
\hline Rio Grande do Norte-RN & $\mathrm{NA \tilde {O }}$ & NÃO & $\mathrm{NA \tilde {O }}$ & $\mathrm{NA \tilde {O }}$ & 49,87 \\
\hline Mato Grosso-MT & NÃO & NÃO & $\mathrm{NA \tilde {O }}$ & $\mathrm{NA \tilde {O }}$ & 46,24 \\
\hline Santa Catarina- SC & $\mathrm{NA \tilde {O }}$ & NÃO & $\mathrm{NA \tilde {O }}$ & $\mathrm{NA \tilde {O }}$ & 40,92 \\
\hline Piauí- PI & $\mathrm{NA \tilde {O }}$ & NÂO & $\mathrm{NA \tilde {O }}$ & $\mathrm{NA \tilde {O }}$ & 37,42 \\
\hline Tocantins-TO & 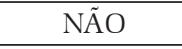 & 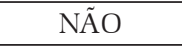 & 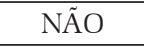 & $\mathrm{NA \tilde {O }}$ & 36,17 \\
\hline Alagoas- AL & $\mathrm{NA \tilde {O }}$ & NÃO & $\mathrm{NA \tilde {O }}$ & $\mathrm{NA \tilde {O }}$ & 35,40 \\
\hline Goiás- GO & $\mathrm{NA \tilde {O }}$ & NÃO & NÃO & 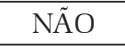 & 34,62 \\
\hline Amazonas-AM & $\mathrm{NA \tilde {O }}$ & NÃO & NÃO & $\mathrm{NA \tilde {O }}$ & 31,42 \\
\hline Rio de Janeiro-RJ & SIM & NÃO & NÃO & $\mathrm{NA \tilde {O }}$ & 28,62 \\
\hline Espírito Santo- ES & NÃO & NÃO & NÂO & SIM & 28,51 \\
\hline Rio Grande do Sul-RS & SIM & SIM & SIM & SIM & 28,35 \\
\hline Minas Gerais-MG & $\mathrm{NA \tilde {O }}$ & SIM & 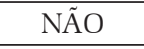 & $\mathrm{NA \tilde {O }}$ & 25,51 \\
\hline Paraíba-PB & $\mathrm{NA \tilde {O }}$ & NÃO & 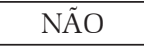 & 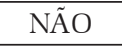 & 24,13 \\
\hline Paraná- PR & $\mathrm{NA \tilde {O }}$ & NÂO & NÃO & $\mathrm{NA \tilde {O }}$ & 22,10 \\
\hline Ceará-CE & $\mathrm{NA \tilde {O }}$ & NÃO & $\mathrm{NA \tilde {O }}$ & $\mathrm{NA \tilde {O }}$ & 19,88 \\
\hline Pernambuco-PE & SIM & $\mathrm{NÂO}$ & NÂO & NÃO & 19,67 \\
\hline Maranhão-MA & NÃO & NÃO & NÂO & NÂO & 18,70 \\
\hline Câmara dos Deputados & SIM & SIM & SIM & SIM & 18,14 \\
\hline Pará-PA & 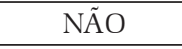 & NÃO & 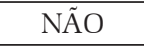 & $\mathrm{NA \tilde {O }}$ & 17,69 \\
\hline Senado Federal & NÂO & NÃO & NÃO & $\mathrm{NA \tilde {O }}$ & 14,35 \\
\hline Bahia-BA & $\mathrm{NA \tilde {O }}$ & NÃO & NÃO & NÃO & 13,95 \\
\hline São Paulo-SP & NÃO & NÃO & SIM & NÃO & 10,63 \\
\hline
\end{tabular}

São Paulo-

$\infty$ Fonte: Como são nossos parlamentares Transparência Brasil (jan. 2008, p.4).

Ф bléia Legislativa do Rio Grande do Sul. No nível

Federal, somente a Câmara dos Deputados cumpre esses requisitos, enquanto o Senado não disponibiliza nenhum deles. Essa ausência de informações, por si só, caracterizaria abuso de poder político em detrimento da sociedade civil. A existência ou não de instrumentos de controle social é um indicativo relevante da consolidação democrática, cuja análise não se restringe apenas ao exercício parlamentar no âmbito da barganha, tramitação e aprovação de projetos em nível quantitativo.

Efetivamente, aCiência Política tem enfatizado, de modo excessivo, as relações procedurais no universo parlamentar, particularmente no Congresso Nacional. Com base nessa ótica, seria possível comprovar a consolidação da democracia a partir da regularidade das eleições, da competição entre os partidos, do jogo parlamentar em nível congressual, da quantidade de projetos e emendas postas em operacionalidade e, sobremodo, da estabilidade das instituições democráticas representativas. ${ }^{2}$

Essa perspectiva restrita da consolidação democrática, com base apenas no exercício legislativo, sem considerar outras relações mais ampliadas e horizontais entre representantes e representados, é o que este artigo pretende refutar, na medida em que se entende que a consolidação

Estão próximos dessas perspectivas os trabalhos de Przeworski, Cheibub e Limongi (2003), bem como Limongi (2006). 
democrática, numa sociedade complexa como a brasileira, não passa exclusivamente por deliberações congressuais e assembleistas. Pelo contrário, a excessiva concentração e a dificuldade de inserção participativa do "cidadão comum" na esfera parlamentar podem depreciar o funcionamento do sistema e contribuir para o seu descrédito junto à sociedade civil.

Em que pese a importância das análises sobre a operacionalização do universo democrático na prática parlamentar, há uma nítida deficiência quanto à relação desproporcional derivada do pleito eleitoral, qual seja, a do distanciamento físico, geográfico e material entre representantes e representados quando se trata do debate, deliberação e decisão política. Em suma, o modelo de democracia representativa vem acentuando o protagonismo dos partidos políticos como atores privilegiados em detrimento da ação coletiva e ativa da sociedade civil (Vazquez, 2001).

Não por acaso o distanciamento entre representantes e representados, no Brasil, se reflete no baixo nível de confiança das instituições políticas em relação àquelas que, tradicionalmente, refletem uma maior proximidade com a sociedade civil, mesmo não sendo pautadas por relações democráticas em suas respectivas organizações. ${ }^{3}$ Pesquisa encomendada pela Associação dos Magistrados Brasileiros, em 2008 (Tabela 3), reflete essa descrença e apatia da sociedade civil em relação aos partidos políticos no Brasil. ${ }^{4}$

Os dados revelam os níveis de descrença e desconfiança acentuados da população quanto aos poderes legislativos, estadual e municipal. Isso reflete, assim, a relação inversa entre a proximidade física dos poderes legislativos dos estados e municípios e a confiança dos cidadãos, e a predominância da esfera Executiva Estadual e Federal no que se refere a uma maior positividade das ações de governo voltadas para a população.

Ademais, e de modo específico, é nítida a desconfiança para com o Poder Legislativo em todas as suas esferas (Federal, Estadual e Municipal), demonstrando, por conseguinte, que a políti-

Tabela 3 - Confiança nas instituições

\begin{tabular}{|c|c|c|c|c|}
\hline Instituições mais confiáveis & Confia & Náo confia & Ns/nr & Saldo \\
\hline Forças Armadas & 79 & 16 & 5 & +63 \\
\hline Igreja Católica & 72 & 24 & 4 & +48 \\
\hline Polícia Federal & 70 & 24 & 6 & +46 \\
\hline Ministério Público & 60 & 30 & 11 & +30 \\
\hline Imprensa & 58 & 33 & 9 & +25 \\
\hline Poder Judiciário & 56 & 37 & 7 & +19 \\
\hline Sindicatos de Trabalhadores & 55 & 38 & 7 & +17 \\
\hline Igreja Evangélica & 53 & 38 & 8 & +15 \\
\hline Governo Federal & 52 & 42 & 6 & +10 \\
\hline Governo Estadual & 49 & 44 & 7 & +5 \\
\hline Instituições menos confiáveis & Confia & Não confia & Ns/nr & Saldo \\
\hline Prefeitura & 47 & 48 & 5 & -1 \\
\hline Empresários & 44 & 45 & 11 & -1 \\
\hline Assembléia Legislativa & 39 & 54 & 7 & -15 \\
\hline Senado & 33 & 61 & 6 & -28 \\
\hline Câmara dos Vereadores & 26 & 68 & 6 & -42 \\
\hline Câmara dos Deputados & 24 & 68 & 7 & -44 \\
\hline Partidos Políticos & 22 & 72 & 6 & -50 \\
\hline
\end{tabular}

Fonte: Associação dos Magistrados do Brasil, maio./jun., 2008.

Amostra de 1.500 entrevistados da população adulta brasileira com acesso à rede telefônica..

${ }^{3}$ Esse argumento pode ser reiterado nos trabalhos de Moisés (2005, 2005a).
${ }^{4}$ Disponível em: www.amb.com.br/portal/docs/pesquisa/ barometro.pdf. A metodologia da pesquisa está detalhada no próprio site de modo a ilustrar melhor o quantitativo pesquisado. 
ca partidária não afeta de modo positivo o cotidiano do eleitor. Chama atenção a baixa credibilidade no empresariado. Isso pode ser interpretado pela associação que o eleitor faz da possível ingerência dos interesses privados na atuação de parlamentares, em detrimento do interesse público.

Por conseguinte, para responder parte dos questionamentos sobre o que causa tal descrença nas instituições políticas brasileiras, é preciso ter em mente que grande parte do distanciamento, da desconfiança e do descrédito pelos quais passa a democracia representativa na atualidade pode ser colocada frente à reprodução constante de antigas formas de exercício do poder político, baseadas na relação entre ordem e obediência, tais como gênero, raça, etnia, status social, ordem econômica, etc. (ONU, 2004). As elites, entes tão nitidamente postos, localizados e distintos, modificaram-se de modo a se confundirem com a própria sociedade, na medida em que a educação, a especialização e a cultura não mais se restringiam a classes específicas.

Essa foi a grande contribuição oriunda da emancipação quantitativa da cidadania através do mercado e das eleições periódicas, o que, do mesmo modo, deu novas roupagens aos instrumentos de abuso de poder, que se sofisticaram a ponto de se fazerem quase imperceptíveis, mesmo nas democracias mais consolidadas (Bobbio, 2002b). De atributo, o poder político passa a ser sinônimo de reputação como capacidade, eficiência e racionalidade de modo a diferenciar o mandatário do representante não pela origem social, mas pelo status de diferenciação intelectual.

Haveria, por conseguinte, algum modelo alternativo a esse estado de conservantismo procedural de democracia? Seriam o associativismo, o comunitarismo, o basismo e o radicalismo soluções para dirimir a excessiva concentração de poderes nos círculos das elites políticas? Como recuperar o sentimento de democracia sem que as próprias instituições democráticas passem por séria desconfiança quanto à sua existência e utilidade?

\section{JOHN DEWEY E A QUALIFICAÇÃO INTELEC- TUAL COMO FERRAMENTA DE NIVELAMENTO DEMOCRÁTICO}

Na medida em que foi enfatizada, até agora, a existência de uma distinção entre governantes e governados e que tal diferenciação se opera cada vez mais sob o estigma da "qualificação" das lideranças político-partidárias, em detrimento da "desqualificação" dos representados, faz-se adequado discutir um modelo alternativo de democracia a partir da reflexão de John Dewey, no que se refere ao nivelamento individual entre governantes e governados.

Dewey define a democracia a partir de uma ótica comunitária e republicana (Honneth, 2001). Contudo, como assinala Pogrebinschi (2004), Dewey diferencia a democracia como idéia e sistema. Essa distinção reflete as preocupações de Dewey com a qualidade não apenas do processo político-eleitoral, mas, sobremodo, com o nível intelectual dos cidadãos sobre os assuntos que incidiam cotidianamente em suas vidas (Hoy, 1998).

Assim, para Dewey, a democracia como "sistema” é aquela dos partidos políticos, eleições, parlamentos, etc. Por seu turno, a democracia como "ideia" é, acima de tudo, um modo de vida (Dewey, 2004). Desse modo, mais que repetição, reprodução e regularidade de procedimentos, a democracia como ideia é virtude e educação cívica, no sentido de que a convivência entre opostos, no ambiente mais próximo do cotidiano do indivíduo, o capacita, através da discussão, para o debate e a compreensão de temas comuns a todos os indivíduos membros de uma comunidade e para a participação qualificada na política (Westbrook, 1993).

Essas considerações são fruto de uma reflexão de Dewey que não separa a política da vida cotidiana, uma vez que a política é a própria vida, dado que a democracia se refere a toda e qualquer experiência nas relações sociais dos indivíduos, de modo que o sistema político reflete o nível de relação que se opera em outras instituições sociais como família, escola, igreja, trabalho, etc. (Dewey, 1997, 2004). A democracia é, pois, um sentimento 
cultivado e desenvolvido ao longo da vida de cada indivíduo, e sua noção de política reflete o tipo de experiência democrática que vivenciou em sua formação (Hoy, 1998).

A democracia se opera desde os primeiros instantes de convivência do indivíduo, na medida em que é a qualidade da comunicação o mecanismo através do qual se forma o homem educado (Dewey, 1997, 2002). Daí a importância dada por Dewey aos processos comunicativos, pois eles provocam a formação, a reflexão e a revisão de conceitos e valores constantemente absorvidos pelo indivíduo ao longo de sua vida (Hickman; Alexander, 1998). Não por acaso Dewey sempre enfatizou a relevância da qualidade dos meios de comunicação como instrumentos necessários à criação de uma sociedade democrática (Dewey, 2003).

A reflexão de Dewey sobre a democracia procura não diferenciar o indivíduo do ponto de vista social, econômico, social e racial, a partir do acesso à informação (Hoy, 1998). Em outras palavras, a educação, entendida como atividade que transcende a instituição escolar, é o veículo para nivelar, de modo concreto, as diferenças ente os indivíduos, operadas na sociedade (Dewey, 2003).

A distinção de ordem intelectual entre os indivíduos tende a desaparecer, na medida em que a educação, como acesso à informação e à formação de qualidade, é implementada (Westbrook, 1993). Com a construção de democracia nesse nível, as instituições políticas tendem a cumprir suas funções de forma pedagógica, dado que a política e, acima de tudo, a democracia passam a ser mais que um sistema; constituem uma ideia que se constrói diuturnamente a partir do compartilhamento de experiências vividas por homens iguais na capacidade de reflexão (Dewey, 2003).

Em suma, para Dewey a política é um dos muitos lugares da democracia (Mogilka, 2003). Desse modo, não pode ser uma espécie de atividade reservada a especialistas iluminados ou iniciados, uma vez que a democracia não se presta, em sua essência, a qualquer tipo de distinção artificialmente construída a partir da origem popular e soberana, mormente, a que alija o cidadão de deci- dir mais amiúde sobre os ditames políticos de qualquer natureza.

\section{OS DÉFICITS DA REPRESENTAÇÃO POLÍTICA E A DIMENSÃO DOS MOVIMENTOS SOCIAIS NO ACCOUUTABILITY ${ }^{5}$}

Partimos do princípio de que é de dentro do paradigma deliberativo de democracia que sobressai a importância dos movimentos coletivos, o papel dos diversos grupos societários e movimentos sociais. Esse campo se apresenta extremamente fértil, diante do tema do afastamento dos governantes em relação aos representados, e principalmente diante da realidade do continente, onde os processos democráticos formais não atendem a determinados segmentos que sempre estiveram em desvantagem.

Compreendemos que o processo deliberativo é inovador para a democracia na medida em que permite que se desenvolvam ajustes para adequála à realidade. Tomamos como ponto de partida a dificuldade que é formar uma vontade geral (no sentido defendido por Rousseau), e que a vontade do povo é manufaturada, que os indivíduos são influenciados e, como não se sentem responsáveis, perdem o senso de realidade. Diante da complexidade da sociedade, é impossível o povo acompanhar as questões de natureza mais técnicas, como

${ }^{5}$ Dewey e Habermas se constituem nos principais teóricos de referência neste artigo. Contudo, é preciso diferenciar e contextualizar suas respectivas reflexóes teóricas sobre a questão da ação coletiva. Dewey analisa a ação coletiva no âmbito da formação do indivíduo em prol do coletivo, o que, para o teórico americano, suplanta a noção de comunidade, tão próxima da cultura norte-americana. Por seu turno, Habermas se posta no exercício da formação de uma vontade coletiva através do debate na esfera pública, permitindo a compreensão da importância dos movimentos sociais. Esse esclarecimento se faz necessário na medida em que há autores que distinguem as concepções de comunidade e ação coletiva entre Dewey e Habermas, dentre os quais Honneth (2001). No entanto, para efeito de corroboração de hipótese, este artigo se concentra na necessidade de não se dispersar a dimensão individual da formação política do indivíduo no âmbito de uma coletividade formal e abstrata, dado que, sem a apreensão individual da realidade, reduzem-se as possibilidades de uma qualificação da política como processo cotidiano coletivo. Para efeito de comparação acerca das concepções norte-americana (comunitarianism) e germânica (gemeinschaftlich) de comunidade, que estão presentes nas reflexões de Dewey e Habermas, ver Brier; Lovelock, 1997. 
afirmava Shumpeter (1984). Segundo esse autor, não haveria o bem comum, pois não haveria o elemento unificador que cimentaria uma democracia, e, assim, o bem comum não se firmaria no plano da lógica, mas sim no dos valores, pois, mesmo quando nos deparamos com situações que envolvem valores considerados universais, como o da saúde, é possível haver dissenso.

Lembramos um caso ilustrativo dessa constatação, que aconteceu aqui no Brasil, durante a primeira república, com a Revolta da Vacina. Mas a lógica de Shumpeter é a de que, na ausência de valor comum definido e diante do nãoenvolvimento do cidadão com as questões públicas, restaria confiar nas formas democráticas procedimentais. Esse distanciamento do individuo da política, visto por Schumpeter (1984) como decorrente do desinteresse e da falta de responsabilidade, é considerado, nos estudos de cultura política, de outra forma. Tal comportamento corresponde à chamada "eficácia política subjetiva”, ou cinismo político, que é a forma como os indivíduos avaliam a sua capacidade de influir ativamente no processo de tomada de decisões políticas e pode ser resultado de uma situação na qual o representado sente que sua atuação não faz qualquer diferença, pois os governantes não levam em consideração as suas opiniões.

Portanto, sem pretender refutar as afirmações desse estudioso, entendemos que é necessário situar os fenômenos apontados dentro de uma lógica conjuntural que compreenda sua gênese.

Diante dessas dificuldades, diríamos que, no lugar da defesa da democracia minimalista e do recurso ao procedimentalismo, seria importante conhecer as relações causais que levam ao quadro político demonstrado por Shumpeter (1984) e criar mecanismos que tornem efetiva a relação entre representante e representado. Assim, invertendo a leitura desse autor, poderíamos afirmar que os indivíduos alijados dos espaços deliberativos se recolhem ao mundo privado. Isso ficou claro, por exemplo, quando alguns dirigentes de Associações de Bairros, "cansados" de demandar ao Estado sem ser ouvidos e atendidos, resolveram voltar-se, após uma dezena de anos de "pressão", para o aproveitamento do espaço físico da Associação, a fim de desenvolver atividades lúdicas (Espiñeira, 1997). Ainda sobre essa questão, podemos observar que a Revolta da Vacina ocorreu num quadro em que dois grupos disputavam o poder político, sem dar a conhecer ou prestar contas à população do que realmente ocorria na esfera dos representantes.

É claro que devemos estar atentos para algumas armadilhas que podem estar contidas nesse debate sobre a esfera das demandas e os agentes estatais e que envolvem a "lógica da sociedade contra o Estado" e dos "movimentos contra os partidos políticos" (Arditi, 1995). Este é um assunto que lança algumas luzes sobre o tema, mas que não é objetivo deste estudo.

Aqui é interessante observar que aquilo muitas vezes é defendido como "vontade geral", na verdade, não passa da "vontade de um grupo que o Estado adota e vende como vontade geral". Seria mais ou menos o que é observado por Habermas (2003b) sobre um tipo de opinião pública que não tem origem nas discussões públicas, mas sim é tornada pública via publicidade.

Para esse autor, se antes, na modernidade, existia uma unidade ética e o elemento unificador era o sagrado, hoje, à medida que a racionalização avança, vive-se a fragmentação das diversas esferas de valor com suas lógicas próprias. Os problemas, portanto, seriam um resultado da fragmentação moderna e do abismo entre os conceitos elitistas - desenvolvidos por distintos especialistas, e os utilizados na vida cotidiana.

Mas, não afetado pelo desencanto de Weber, Habermas consegue ver a possibilidade da existência de alguns instrumentos de mediação que serviriam de ponte entre essas diversas esferas fragmentadas (da política, da ciência, da arte, da religião, dentre outras), recuperando-se, assim, o mínimo senso de totalidade perdido e dando sentido para a vida e para a sociedade. Ele acredita na possibilidade de se criarem instrumentos que possam assegurar certa unidade ao mundo da vida (que é o pano de fundo das convicções partilhadas por todos os sujeitos que agem comunicativamente). 
É nesse quadro que o Habermas dos anos noventa vai oferecer espaço para introdução do tema dos movimentos sociais. É nessa década que ele vai reconhecer o caráter totalizante do conceito de indústria cultural, que concebe o indivíduo, na sociedade de massa, como um consumidor passivo dos produtos culturais. Essa idéia é incompatível com a sua teoria do agir comunicacional - baseada em valores compartilhados e no diálogo racional entre sujeitos ativos - que, portanto, precisa ser abandonada. Isso vai ocorrer principalmente à luz das novas teorias da comunicação, que enfatizam o processo de atribuição de sentido (negociada) que ocorre na esfera da recepção.

Essa virada recupera o significado normativo do conceito de esfera pública que aparece no advento da modernidade. Cria o espaço que é o da sociedade civil, locus privilegiado para o funcionamento dos movimentos sociais e grupos. Nesse sentido Avritzer e Costa (2004) afirmam que o conceito da esfera pública cria um espaço, que é o da sociedade civil, e estabelece uma argumentação com o Estado. Ela seria o lugar para toda uma gama de experiências comunicacionais originárias da sociedade civil, com a introdução de novos temas e públicos, o que contribuiria para politizar questões do mundo da vida na esfera pública. Para Habermas, existe uma tensão entre a esfera pública e o Estado. É esse processo de ação comunicativa que vai levar ao ponto de "validade moral", estabelecendo um código compartilhado e tornando, assim, possível a formação da vontade geral, em que os elitistas não acreditavam.

Nesse ponto, é necessário atentar para os limites que Andrew Arato (2002) estabelece na ação da sociedade civil e de seus movimentos. Ele acredita na importância da pressão da sociedade civil como um complemento para um regime representativo, na promoção de mecanismos de responsabilização, mas ressalta que essa ação não pode ter o sentido da transgressão, da desobediência civil, pois esses movimentos representam apenas uma pequena parte dos cidadãos. Para ele, é necessário, portanto, preservar o que está definido no modelo institucional, garantindo-o e cumprindo-o. $\mathrm{O}$ au- tor nega, assim, a ação direta, ao apontar para a relevância da sociedade civil no modelo de accountability. "A esfera pública e a sociedade civil atuariam de forma complementar, ao invés de substituir os processos de accountability" (Arato, 2002, p. 97).

Isso nos leva a considerar não uma recusa da democracia como procedimento, nem que é necessário obrigatoriamente aliar-se à "democracia selvagem” na defesa de uma virada de jogo. Mas é necessário observar-se que, no Brasil, os movimentos sociais têm atuado muitas vezes no sentido de fazer valer a Constituição, ou seja, atuam para que o plano "de jure" seja passado para o plano real, para o cumprimento da lei. Isso porque, como defende Emir Sader (2003), a elaboração e a aprovação da Constituição de 1988 ocorreram na contramão de um mercado que chegava atrasado ao Brasil, com suas políticas de ajuste fiscal, de modo que, nos anos noventa, o Brasil passou a ser uma democracia sem cidadãos, em que os direitos sociais foram reconhecidos formalmente, ao mesmo tempo em que ocorre a redução e o corte nos direitos sociais.

Acompanhando o quadro dos movimentos sociais, percebemos que eles, na década de oitenta, no Brasil, provocaram mudanças nas práticas jurídicas e no modo de implantar algumas políticas sociais (onde existiam mobilizações populares). Hoje, como dissemos, eles têm tido como um dos seus destacados papéis o de colocar no plano real o que está na lei, ou seja, sua prática cotidiana está muitas vezes entre o "espaço da lei e sua aplicação”. O que não é pouco, considerando a nossa realidade.

É levando em conta esse contexto que, em alguns momentos, a utilização da ação direta ajuda a formar uma opinião pública, generalizando a experiência de comunicação dentro de um grupo, como ocorreu com a revolta dos estudantes secundaristas contra o aumento das passagens dos ônibus, em Salvador. Esse movimento, que ficou conhecido como "Revolta do Buzú", provocou a paralisação da cidade por uma semana e ocorreu através dos órgãos de representação estudantil (grê- 
mios e DAs), com o apoio de partidos políticos, conseguindo atrair os representantes através da esfera pública por meio da exposição de uma opinião pública.

Nesse sentido, o movimento conseguiu que os representantes políticos sentassem com os principais envolvidos para sentir as demandas e acompanhar o sentimento de uma grande parte da população. Essa experiência demonstrou como os movimentos sociais podem, através da organização e da informação, levar o cidadão a se sentir parte da sociedade política, estabelecendo temas, instruindo, orientando e organizando os representados na esfera pública, o que permite que os representantes repensem seus atos nesse processo. Esse exemplo demonstra que, em alguns momentos, a ação direta pode provocar e formar a opinião pública, generalizando a experiência de comunicação dentro de um grupo.

Merece também destaque um movimento semelhante ao de Salvador, ocorrido com estudantes secundaristas no Chile, em 2006, denominado Revolta dos Pingüins. ${ }^{6}$ Esse movimento se iniciou com a demanda de passes escolares para utilização dos transportes. Ele tomou as ruas e ocupou os colégios durante um mês. Foram 100 mil estudantes que paralisaram todos os colégios, inclusive os privados, que participaram com o sentido de oferecer solidariedade. Da reivindicação inicial, o movimento passou a demandar outras questões de natureza mais política, como reformas no sistema da educação privada e a denunciar injustiças provocadas pelo neoliberalismo. Esse movimento tomou um impulso, fez cair um Ministro e trouxe adesões de trabalhadores "obreros", do segmento da saúde, professores e alunos de universidades e os pais dos estudantes. Alguns entrevistados afirmam que todo o país estava com os estudantes. Entre as questões colocadas, estava a defesa da formação de um conselho cidadão que abrigaria diversos atores sociais e políticos.

Na Bahia, merece destaque a aprovação da

- Assim chamado em alusão aos uniformes utilizados pelos estudantes secundaristas (camisa branca, casaco em formato $\mathrm{V}$ preto, jaqueta e gravata.
Lei, que ocorreu há aproximadamente um mês, que estabelece um processo eleitoral para os cargos de diretores dos colégios públicos do Estado e que envolve professores, técnicos administrativos e alunos. Essa conquista foi resultado de demanda e da pressão de diversos movimentos dos estudantes e professores.

Observa-se também, nesses movimentos, assim como na Revolta do Buzú, a formação de um espaço público através da pressão resultante de ação direta, como no caso da formação desse conselho com membros do governo, personalidades da sociedade civil e movimentos sociais. Mas não se pode deixar de destacar também a força dos donos dos colégios privados, que ficou patente nessas negociações, como pode ser observado numa entrevista com uma das estudantes participantes da Revolta dos Pingüins (Pronzato, 2007)

De todo modo, é revelador, nas declarações de participantes das chamadas bases desses dois movimentos, e mesmo em outros movimentos sociais, a ênfase dada ao processo de aprendizagem que ocorre durante a participação nas ações empreendidas. Elas afirmam que só a partir desse engajamento passaram a saber o que ocorria com o país. É muito comum, na prática dos movimentos sociais, a formação, durante as ações coletivas, de uma ação pedagógica de conhecimento e de tomada de consciência, além de elas servirem como "sensores" para informar o sistema político. Quando Sartori (1994) enfatiza a importância da democracia representativa, referindo-se à falta de representatividade da "democracia de manifestação" - marchas, passeatas, que, mesmo envolvendo mais de 10.000 participantes, sempre estariam bastante abaixo em comparação com o número de votantes que participam de eleições -, desconsidera o potencial educador dessas manifestações, que realizam um contrapeso aos meios de comunicação. Esse processo leva ao esclarecimento do representado, o que pode vir a provocar a distribuição de recursos e o sentimento de "reconhecimento", que teriam papel central no mecanismo de accountability.

Melucci (2001) observa que é através das 
lutas parciais que se potencializa a formação de identidades, pois elas são resultado de um processo de negociação contínua, ou, como defende Ernesto Laclau (2006), demandas crescentes e não satisfeitas criam uma relação que ele denomina como "equivalencial”, relação essa que pode ser responsável pela constituição de um povo no sentido geral. Ele exemplifica:

... suponhamos que em uma certa localidade um grupo de vizinhos solicita à prefeitura que crie uma linha de ônibus para ajudar a levá-los do lugar em que vivem até o lugar em que a maioria trabalha. E uma demanda muito específica e atual. Com efeito, a prefeitura pode aceitar essa demanda, o que seria o fim do problema, ou pode também recusá-la. Se a prefeitura recusa, haverá uma frustração dessa demanda. E, se a gente começa a ver que naquela área em que eles vivem há outras demandas, como na área de habitação, educação, segurança, distribuição de água, que tampouco são satisfeitas, isso começa a criar um sentimento básico de solidariedade entre todas essas demandas (2006, p. 22-23).

Nessa lógica interativa, novas questões vão surgindo. Por exemplo, os debates sobre o melhoramento das ruas da minha cidade e as tematizações de novas questões podem levar à superação dos fins imediatos.

Assiste-se, neste momento, a uma pluralidade de movimentos coletivos. Esses diferentes atores coletivos oferecem uma ressignificação simbólica de identidades e, muitas vezes, criam sujeitos com capacidade globalizantes.

Sabemos que, nesse campo, as questões são mais férteis do que as respostas. Mas o que tentamos discutir aqui é como superar o autointeresse, na direção do "interesse bem compreendido", e reduzir o distanciamento entre representantes e representados, sem desconhecer a dificuldade da construção de um modelo teórico global de ação social a partir da heterogeneidade dos movimentos sociais, diante de uma conjuntura denominada por Lavalle (2007) como "pós partidária", em que os atores não mais se identificam com os partidos. Eles vivenciam a fragmentação da classe trabalhadora, e os partidos políticos de massas já não criam identidades.

Nos movimentos sociais atuais, assistimos, muitas vezes, ao fato de que suas estruturas internas diminuem, cada vez mais, a hierarquização e o conteúdo de suas práticas e se afasta dos projetos considerados finalísticos. Formas democráticas com algumas características inovadoras e, em certa medida, não reduzíveis às praticas partidárias tradicionais têm surgido com frequência nos últimos anos. Esses movimentos apresentam elementos que apontam para ações estimuladoras da formação de cidadãos informados, que acompanham os acontecimentos políticos. Diante dessas inovações, defendemos a tese de que os movimentos sociais oferecem elementos para os representantes políticos abertos à "revisão e reavaliação de suas práticas", considerando o que Urbinati nos informa:

... a refrega política, que a representatividade da representação traz à tona, uma característica que é sempre uma questão de grau e flutuação, e uma construção ideológica que está sempre aberta à revisão e à reavaliação (2007, p. 210).

Concluindo, acreditamos que é no quadro da esfera pública, nas constantes negociações, que os movimentos sociais vão exercer o papel político de exigir que se cumpram as grandes funções dos representantes, estimulando o estabelecimento do elo conectivo com os representados. Além de, nessas práticas dos movimentos sociais, serem construídos sujeitos sociais capazes não só de fornecer informações ao sistema político sobre o que está ocorrendo na sociedade civil, mas também de dar visibilidade às suas demandas e, assim, estar sempre a reorientar o representante.

Como Arato (2002), acreditamos que o accountability que ocorre nas eleições através da punição do representante só pode se realizar, de fato, se o financiamento das candidaturas dos representantes deixar de ter origem privada. Isso porque os recursos privados contribuem para que o candidato não se preocupe com os eleitores, mesmo que pense em reeleição, pois o volume de recursos fornecidos por esses grupos garantiriam uma publicidade capaz de maior convencimento e favorecimento de "grupos frágeis". É bastante conhecida, no caso do Brasil, essa dinâmica, com o retorno, via eleição, de representantes que tiveram 
uma trajetória de déficits profundos na sua prática governativa, mas cuja reeleição foi garantida por intermediação da mídia entre a sociedade, os representantes e os recursos privados. ${ }^{7}$

Entendemos que os movimentos sociais são grandes agentes para o aprimoramento do âmbito institucional, como sensores da sociedade civil e formadores e informadores dessa própria sociedade, destacando a mão dupla desse processo: o fortalecimento da esfera pública dentro de um regime que a fortaleça e seja fortalecido. Como aponta Miguel (2002), "o ideal democrático continua exibindo o seu caráter subversivo”, pois os regimes democráticos, cada vez mais dilatados, é que vão fortalecer a esfera pública e vice-versa. Acreditamos que a ampliação do direito civil e político, defendida por Habermas, pode trazer as mudanças desejadas nos planos mais importantes - social e econômico. Defendemos que é através da formação do homem, de Dewey, e na crença no debate na esfera pública, que se cria um processo capaz de estabelecer uma agenda comum, com interesses públicos a serem delineados e que, juntamente com as práticas de prestação de contas dos representantes e o controle social, pode-se criar um caminho fértil para a formação de uma nova subjetividade, percebendo-se então, nesse processo, o ponto de contato entre Dewey e Habermas.

(Recebido para publicação em outubro de 2008) (Aceito em dezembro de 2008)

7 Casos recentes evidenciam essa fragilidade do mecanismo de responsabilização, como ocorreu com um dos "anões do orçamento", que, depois dos "escândalos" relacionados à elaboração do orçamento para o país, se elegeu prefeito numa cidade da Bahia e, mais recentemente, em outubro de 2008, com a eleição do prefeito de Manaus, cuja história é repleta de escândalos de corrupção. Assim, além da saída apontada por Arato, defendemos a tese de que o "vestígio" do candidato só pode ser recuperado com debates, numa realidade de ações coletivas, exatamente de movimentos sociais, que poderíamos chamar um processo surgido de "baixo" e também uma ação pedagógica formada em vários espaços, como aponta Dewey.

\section{REFERÊNCIAS}

ARATO, Andrew. Representação, soberania popular e accountability. Lua Nova: revista. de Cultura e Política, CEDEC, n. 55/56, 2002

AVRITZER, Leonardo; COSTA, Sergio.Teoria crítica, democracia e esfera pública: concepções e usos na América Latina. DADOS: revista de Ciências Sociais, Rio de Janeiro, v. 47, n. 4, 2004.

BAUMANN, Z. Em busca da política. Rio de Janeiro: Jorge Zahar, 1999.

BEITZ, C. R. Political equality. An essay in democratic theory. Princeton: Princeton University Press, 1989.

BOBBIO, N. Elogio da serenidade. São Paulo: UNESP, 2002a.

. O filósofo e a política. Antologia. Rio de Janeiro: Contraponto, 2003.

O futuro da democracia. 8.ed.. Rio de Janeiro: Paz e Terra, $2002 \mathrm{~b}$

BRASIL. Constituição da República Federativa do Brasil. Brasília: Senado Federal, 2007.

BRIER, Alan; LOVELOCK, Robin (Ed.). Communication and community. Anglo-American Perspectives. New York: Averbury, 1997.

CASTEL, R. La Metamorfosis de la cuestión social. Buenos Aires: Paidós, 1995.

COHEN, J; ARATO, A. Civil society and political theory. Massachussetts: The MIT Press, 1999.

COMPARATO, F. K. Ética, direito, moral e religião no mundo moderno. São Paulo: Companhia das Letras, 2006.

DEWEY, J. Democracy and education. New York: Dover, 2004. Experience and education. New York: Simon \& Schuster, 1997

Human nature and conduct. An introduction to social psychology. New York: Dover, 2002.

. My pedagogic creed. New York: Dover, 2003.

ESPIÑEIRA, M. V. O partido, a igreja e o Estado nas Associações de Bairros. Salvador: Edufba, 1997.

FISHER, R; SHARP A. Getting it Done. How to lead when you're not in charge. New York: Harper Perennial, 1998.

HABERMAS, J. A Inclusão do outro. Estudos de teoria política. São Paulo: Loyola, 2003a.

Mudança estrutural da esfera publica. Rio de Janeiro: Tempo Brasileiro, 2003b.

Direito e democracia: entre facticilidade e validade. Rio de Janeiro: Tempo Brasileiro. v.1, 2.

.Teoría de la acción comunicativa: complementos y estúdios previos. Madrid: Ediciones Cátedra, 1997.

HICKMAN, L.; ALEXANDER, T. (Ed.). The essential dewey. Bloomington: Indiana University Press, 1998. $2 \mathrm{v}$

HONNETH, Axel. Democracia como cooperação reflexiva. Jobn Dewey e a teoria democrática hoje. In: SOUZA, Jessé (Org.). Democracia hoje. Novos desafios para a teoria democrática contemporânea. Brasília:Unb, 2001.

HOY, T. The political philosophy of John Dewey. Towards a constructive renewal. New York: Praeguer, 1998.

LACLAU, Ernesto. Inclusão, exclusão e a construção de identidades. In: AMARAL Ir Aécio; BUTITY, Joanildo A. Inclusão social, identidade e diferença. São Paulo: Annablume, 2006. 
LEFORT, C. Pensando o político. Ensaios sobre democracia, revolução e liberdade. Rio de Janeiro: Paz e Terra, 1991.

LIMONGI, F. A Democracia no Brasil. Presidencialismo, coalizão partidária e processo Decisório. Novos Estudos CEBRAP, São Paulo, n. 76, nov., 2006.

LOCKE, J. Dois Tratados sobre o governo. São Paulo: Martins Fontes, 1998.

MAQUIAVEL, N. Comentários sobre a primeira década de Tito Lívio. 3.ed. Brasília: UnB, 1994.

O príncipe. São Paulo: Nova Cultural, 1996.

MELUCCI, Alberto. A invenção do presente: movimentos sociais nas sociedades complexas. Rio de Janeiro: Vozes, 2001

MICHELS, R. Political Parties. A sociological study of the oligarchical tendencies of modern democracies. 2.ed. New York: The Free Press, 1968.

MIGUEL, Luis Felipe. A Democracia domesticada: bases antidemocráticas do pensamento democrático contemporâneo. DADOS: revista de Ciências Sociais, Rio de Janeiro, v. 45, n.3, 2002.

MOGILKA, M. Educar para a democracia. Cadernos de Pesquisa, Curitiba, n.119, jul., 2003.

MOISÉS, J. A. A. Desconfiança nas instituições democráticas. Opinião Pública, Campinas, n. 1, mar., 2005a. v. 11.

Cidadania, confiança e instituições democráticas. Lua Nova, São Paulo, CEDEC, n. 65, 2005 b. 1995.

. O brasileiros e a democracia. São Paulo: Ática,

MONTESQUIEU, Charles de Secondat. Do espírito das leis. 2.ed. São Paulo: Companhia das Letras, 2000.

PINTO, Celi. Notas sobre a controvérsia Fraser-Honneth informada pelo cenário brasileiro. IN: CONGRESSO BRASILEIRO DE SOCIOLOGIA, 13. Recife, UFPE, 2007.

PIRES, Francisco Murari. A razão da democracia e a Astúcia da demagogia. Revista Tempo Brasileiro, n. 154, jul./ set., 2003.

PNUD. Programa das Nações Unidas para o Desenvolvimento. A Democracia na América Latina. Rumo a uma democracia de cidadãos e cidadãs. São Paulo: LM\&X, 2004
POGREBINSCHI, T. A Democracia do homem comum: resgatando a teoria política de John Dewey. Revista de Sociologia e Política, Curitiba, n. 23, nov., 2004.

PRZEWORSKI, A; CHEIBUB, J. A; LIMONGI, F. Democracia e cultura. uma visão não culturalista. Lua Nova, São Paulo, CEDEC, n.58, 2003.

PRONZATO, Carlos. La rebelión pingüina: los estudiantes secundários chilenos contra el sistema. Santiago do Chile: Lamestiza Audiovisual, 2007. 1 CD-Rom

ROUSSEAU, Jean- Jacques. O contrato social. São Paulo: Ed Cultrix , 2004

SADER, Emir. A refundação do Estado e da política. In NOVAES, Adauto. A crise do Estado-Nação. Rio de Janeiro: Civilização Brasileira, 2003.

SARTORI, G. A teoria da democracia revisitada. São Paulo: Ática, 1994.

SCHUMPETER, Joseph. Capitalismo, socialismo e democracia. Zahar Editores, 1984

SUSSKIND, L; CRUIKSHANK, J. Breaking the impasse. Consensual Approaches to Resolving Public Disputes. Vancouver: Basic Books, 1987.

TIRONI, E. La Irrupción de las masas y el malestar de las elites. Santiago de Chile: Grijalbo, 1999.

URBINATI, Nadia. O que torna a representação democrática? Lua Nova: revista. de Cultura e Política, São Paulo, CEDEC, n. 67, 2006.

VÁZQUEZ, R. Liberalismo, estado de derecho y minorías. México DF: Paidós, 2001.

VERBA, G. Comparative polítics. A theoretical framework. New York: Harper Collins, 1996.

WEBER, M. Conceitos sociológicos fundamentais. Lisboa: Edições 70, 2005.

Economia y sociedad. Ciudad de México: Fondo de Cultura Económica, 1993.

WESTBROOK, R. B. John Dewey and american democracy. Cornell: Cornell University Press, 1993.

WILDAVSKY, A. Speaking truth to power. The art and craft of policy analysis. Boston: Little Brown, 1979. 


\section{DEMOCRACY, SOCIAL MOVEMENTS AND \\ INTELLECTUAL LEVELING: considerations about the enlargement of political participation}

\author{
Maria Victória Espiñeira \\ Helder Teixeira
}

This paper has for theme the subject of the democratic legitimacy underlining, for such, the limits of representative democracy and the potentialities dammed inside of current political Brazilian spectrum of individual and collective action, supplanting the quantitative bias that prevails in the analyses on the democratic process in Brazil. Beyond the variables traditionally seated in the triad vote, political parties and elections, this paper tries to demonstrate that the Brazilian electoral democracy still didn't consolidate a democratic political culture, in the measure in that it is solidifying a differentiation plane between representatives and represented, due to mandates more and more imperatives and less bound to the control and participation of those represented. Quantitative researches, primary sources, secondary sources and the analysis of recent social movements in the national scene allowed the building of the hypothesis worked here that the electoral process, for itself, doesn't answer for the construction and consolidation of a plural and participative democracy.

Keywords: democracy, representation, social movements, public sphere, accountability.

\section{DEMOCRATIE, MOUVEMENTS SOCIAUX ET REMISE A NIVEAU INTELLECTUEL: considérations sur l'accroissement de la participation politique}

\author{
Maria Victória Espiñeira \\ Helder Teixeira
}

Le thème abordé dans cet article est celui de la question de la légitimité démocratique. Pour ce faire, les limites de la démocratie représentative ainsi que les potentialités retenues dans le spectre politique actuel brésilien d'une action individuelle et collective ont été mises en évidence, allant au-delà de l'aspect quantitatif prédominant dans les analyses du processus démocratique au Brésil. Pour dépasser les variables traditionnellement établies sur la triade vote, partis politiques et élections, nous essayons de montrer que la démocratie électorale brésilienne n'a pas encore réussi à consolider une culture politique démocratique, dans la mesure où elle renforce un plan de différentiation entre représentants et représentés, dû à des mandats de plus en plus impératifs et de moins en moins habitués au contrôle et à la participation des représentés. Des recherches quantitatives, des sources primaires, secondaires et l'analyse de mouvements sociaux récents sur la scène nationale ont permis de construire l'hypothèse selon laquelle le processus électoral, en soi, n’a aucun répondant pour la construction et la consolidation d'une démocratie plurielle et participative.

Mots-CLÉs: démocratie, représentation, mouvements sociaux, sphère publique, accountability.

Maria Victória Espiñeira - Professora Adjunta do Departamento de Ciência Política e da Pós-Graduação em Ciências Sociais da UFBA. É mestre em Ciências Sociais e doutora em Ciência e Filosofia da Educação. Tem pesquisado sobre os movimentos sociais e suas relações com os partidos políticos (com ênfase nos estudantes e nos bairros), os vereadores e a presença dos movimentos sociais nas suas agendas, a cultura política desses grupos políticos e a transição democrática no Brasil. Publicou O Partido a Igreja e o Estado nas Associações de Bairros pela EDUFBA (1997), o capítulo "Experiência da Ala Jovem do MDB da Bahia durante o Regime Militar (2003) e vários artigos sobre movimento estudantil.

Helder Teixeira - Licenciado e bacharel em História pela UFRN, mestre em Ciência Política pela UFPE e doutorando em Ciências Sociais da UFBA. Atua no campo da assessoria e consultoria parlamentar ad hoc na Câmara Municipal de Aracaju (SE), como colunista do Jornal CINFORM e comentarista político em rádio e televisão no estado Sergipe. Desenvolve pesquisa sobre a ingerência militar na Constituinte de 1987-1988 e seus desdobramentos no âmbito da segurança pública brasileira hodierna através de Bolsa da CAPES. 